\title{
Author Correction: Distinct temporal integration of noradrenaline signaling by astrocytic second messengers during vigilance
}

\author{
Yuki Oe, Xiaowen Wang, Tommaso Patriarchi, Ayumu Konno (D, Katsuya Ozawa, Kazuko Yahagi, \\ Hirokazu Hirai (D), Takashi Tsuboi, Tetsuya Kitaguchi, Lin Tian (D), Thomas J. McHugh (1) \& Hajime Hirase (D)
}

Correction to: Nature Communications https://doi.org/10.1038/s41467-020-14378-x, published online 24 January 2020.

The original version of this Article omitted from the author list the 8th author Takashi Tsuboi who is from the 'Department of Life Sciences, Graduate School of Arts and Sciences, The University of Tokyo, 3-8-1 Komaba, Meguro, Tokyo 153-8902, Japan' and the 9th author Tetsuya Kitaguchi who is from the 'Laboratory for Chemistry and Life Science, Institute of Innovative Research, Tokyo Institute of Technology, 4259 Nagatsuta-cho, Midori-ku, Yokohama, Kanagawa 226-8503, Japan'. Consequently, the corrected version of the Acknowledgements removes the following from the original version: 'Dr. Tetsuya Kitaguchi for providing Pink Flamindo construct.' Additionally, the following was added to the Author contributions: 'T.T. and T.K. shared and discussed unpublished Pink Flamindo data.' This has been corrected in both the PDF and HTML versions of the Article.

Published online: 07 July 2020

\footnotetext{
(c) (i) Open Access This article is licensed under a Creative Commons Attribution 4.0 International License, which permits use, sharing, adaptation, distribution and reproduction in any medium or format, as long as you give appropriate credit to the original author(s) and the source, provide a link to the Creative Commons license, and indicate if changes were made. The images or other third party material in this article are included in the article's Creative Commons license, unless indicated otherwise in a credit line to the material. If material is not included in the article's Creative Commons license and your intended use is not permitted by statutory regulation or exceeds the permitted use, you will need to obtain permission directly from the copyright holder. To view a copy of this license, visit http://creativecommons.org/licenses/by/4.0/.
}

(C) The Author(s) 2020 